Discussion.-The diagnosis in this case was not difficult. It was clear that the greatly enlarged heart indicated a severely damaged myocardium, and that the implication of the conducting system had led to heart-block. Several postgraduates assumed that the auricular-ventricular dissociation was complete, and had not considered the possibility of a $2:$ I partial heart block. When complete heart block exists, the auricles and ventricles synchronise more or less exactly from time to time, producing variability and sometimes reduplication of the heart sounds. The presence of this sign and the constancy of the heart rate indicated in this patient the true nature of the arrhythmia. Regarding ætiology, it was suggested by some post-graduates that syphilis was the probable factor. At later ages (as in this patient) coronary sclerosis is a much commoner cause of heart block, while the nature of the history and the presence of generalised cardiovascular disease supported this view of the ætiology. The nature of the epigastric pain ensuing upon exertional dyspnœa was discussed. This pain was probably not of coronary origin. When paroxysmal pain related to exertion occurs in the epigastrium as a sequel to dyspnœe and does not radiate, it is believed to originate in ventricular stress rather than in myocardial ischæmia. The high systolic pressure in this patient, and the large pulse pressure (I30) are in part related to the arterial condition. They are also in a measure compensatory, and due to the complete filling of the heart during the long period of relaxation, followed by a correspondingly augmented stroke volume.

\title{
CASE DEMONSTRATED AT THE F.R.C.S. CLASS.
}

Case presented by PERCIVAL P. COLE, F.R.C.S.

Mr. S. B., Aged 34. Occupation, Labourer.

Complaint.-Swelling on inner side of left thigh.

Duration: Two months.

History.-Noticed swelling 2 months ago, accidentally, which gradually increased to the present size. One week before admission he developed pain in the swelling. Has been in the country all his life. No history of venereal infection.

Previous History: Nil of importance.

Family History: 3 children, well.

On Examination.-Large elongated swelling on inner side of thigh extending from middle of thigh up to pubic ramus. No enlarged veins.

Palpation.-Consistency: Soft, no fluctuation, hard nodule at upper end. Surface smooth. Edge merges into surrounding tissue.

Relation: Adductor longus and gracilis muscles anteriorly. Hamstring muscle behind becomes fixed on contraction of adductor magnus. Not compressible and no murmur on auscultation.

Special Examination. W.R.: Negative. Hydatid skin test: Positive. $6 \%$ eosmophilia.

Pre-Operative Diagnosis._-Intra muscular sarcoma, Lipoma or Fibroma. 


\section{Operation.-Tumour removed situated in adductor magnus.}

\section{Post-Operative Diagnosis.-Hydatid cyst, secondarily infected.}

Comments. -No candidate, to the best of my recollection, mentioned the possibility of hydatid disease. I myself inclined to the diagnosis of sarcoma, but was careful to point out that, of the parasitic lesions of muscle, hydatid disease could not be excluded. At the time of demonstration the hydatid skin test and blood count had not been investigated. The progress of the case has been uneventful.

\section{REVIEW.}

\section{ACTINOTHERAPY TECHNIQUE.}

An outline of indications and methods for the use of modern light therapy, with a foreword by Sir Henry Gauvain. The Sollux Publishing Company 1933, Slough. Price 6/-.

"Actinotherapy Technique," issued and published by the Sollux Company gives in short form a comprehensive survey of the physics, physiology, and methods of use of light and heat derived from an artificial source. Since actinotherapy became more generally employed it has shown itself of great practical value in a certain group of conditions ; the field has, however, become restricted as the result of accumulated experience and we imagine few would now accept many of the claims of almost universal benefit which the earlier enthusiasts allowed themselves to make. This criticism, which we believe would not now be controverted, has an especial application here for in Part II in an alphabetical index of diseases very many and very varied conditions are mentioned as amenable to light treatment. We are told, for example, that the common cold is readily aborted by a sterilizing dose of ultra violet rays to both nostrils, the naso-pharynx, and tonsils. If this comparatively simple procedure is so efficacious, colds would disappear whereas we know that this minor scourge is as prevalent now as formerly.

Again under tinea it is stated that the trichophyton fungus on the scalp, etc., readily yields to actinotherapy : nevertheless dermatologists who are fully informed as to the uses of "light" continue to employ
$\mathrm{X}$-rays or thallium acetate in the treatment $\mathbb{\Phi}$ of ringworm of the scalp.

Critics are among those who live in glass houses. To evade the inevitable consequences let it be added that the statements made in the above mentioned paragraphs, and indeed throughout Part II, are all taken from written papers or works of reference and are therefore backed by authority. They enable the reader to see what has been proposed and done although he may not by a similar technique always attain the desired end.

Part I deals with physical data, physiological effects, and dosage. We imagine this will prove of immense value not only to those who are beginners, but even to the practitioner who may have already acquired experience. The chart on Page $\mathbf{4 3}$ gives an admirable summary of the system of dosage with the different forms of lamp.

As we have already mentioned above a considerable and comprehensive bibliography is supplied which greatly enhances the value of the little book.

In a foreword Sir Henry Gauvain gives it as his opinion that the handbook will be regarded as indispensable to all engaged in the practice of actinotherapy. With the opinion of this authority we readily concur. 